\title{
Isolated anencephaly/exencephaly
}

\author{
INSERM
}

\section{Source}

INSERM. (1999). Orphanet: an online rare disease and orphan drug data base. Isolated anencephaly/exencephaly. ORPHA:1048

Anencephaly is a neural tube defect. This malformation is characterized by the total or partial absence of the cranial vault and the covering skin, the brain being missing or reduced to a small mass. Most cases are stillborn, although some infants have been reported to survive for a few hours or even a few days. 